\title{
Vigilance for Sale of Drugs through Online Pharmacies
}

\author{
Purva Samant* and Ashwini Deshpande \\ SVKMS NMIMS School of Pharmacy \& Technology Management, India \\ *Corresponding author: Purva Samant, SVKMs NMIMS School of Pharmacy \& Technology Management, Shirpur, Maharashtra- 425405, India \\ Submission: 侮 March 22, 2018; Published: 制 May 18, 2018
}

\begin{abstract}
The sale of drugs through online pharmacy has emerged all over the globe. These online pharmacies aid in doorstep delivery of medicines hence proving to be convenient for the patient. But the 'Online Pharmacy' concept has drawn a lot of skepticism owing to many online-fraud cases and counterfeiting of drugs. To prevent these mishaps there are no stringent guidelines put forth as those of the sale of drugs in shops. This short communication focuses of the pros and cons of ordering drugs from online pharmacies. Highlights of the Indian scenario of sale of drugs through online pharmacies are discussed. Also, it gives recommendations to tackle illegal sale of drugs with reference to USFDA guidelines for the same and a list of organisations aiding the legitimate sale of drugs through online pharmacies.
\end{abstract}

Keywords: Online pharmacy; Drug abuse; Counterfeiting; Prescription drugs; Internet; Regulations

\section{Introduction}

The internet has taken over the world in all aspects. Not sparing any field,it is not surprising that even pharmacies have gone online. An online pharmacy refers to a business organisation that is involved in sale of pharmaceutical preparations like non- prescription and prescription-only drugs, by ordering them online and delivery through mail. The sale of drugs over the internet began in the late 1990s and has expanded to an extent that the US Food and Drug Administration (FDA) has devoted a complete section on its official website to "Buying medicines over the Internet". Online pharmacy business, as a matter of fact, has drawn a lot of skeptism as the responsibility of securing mankinds health lies on the shoulders of Pharmacists. Due to many reported cases of online fraud and counterfeit of the drugs [1], a few regulatory bodies,majorly the USFDA has given certain guidelines to the people to stay vigilant against illegal online pharmacies. Nevertheless, whether these online pharmacies is a boon or bane still remains questionable. The online pharmacy companies themselves can undertake stringent routine steps to not just secure their reputation but also save lives of the end user by providing quality services and medicines.

\section{Pros of an online pharmacy}

Online pharmacies are very convenient. An order can simply be placed online and the medicines get delivered at our doorstep. In contrast to the pharmacy shops, there is no need to drive to a pharmacy each time with our prescription and wait for our turn to buy medicines. If a patient suffers from a chronic condition requiring medications monthly, he can avoid multiple trips to the pharmacy by getting his prescriptions sent to him on a monthly basis. The elderly or the disabled and patients residing in remote areas can access drug information, various products and services with ease on contrary to earlier difficult scenario [2].

Since these pharmacies don't require a physical set up for the sale of drugs but just a warehouse for stocking medicines, there is a lot of cost cutting and drugs can be sold at low prices. In the USA, generally medicines are sold at a 10\% lower rate despite of transportation charges [3].

Facilities like Health Vault are also offered where the patient data is stored and updated regularly for future recommendations.

\section{Cons of an online pharmacy}

Besides not getting the medicines on the same day as you ordered them, online pharmacies also cannot keep a personal check on the patient in case of any negative drug interactions. The pharmacy must have a registered pharmacist on contrary to which some online pharmacies which dispense medicines without having a registered pharmacist on board. Illegal online pharmacies sell drugs even without asking for a prescription. Many online pharmacies do not protect your financial and personal information, this could lead to fraud. There are a few Pharmacy websites that do not publish their contact information and to worsen it more they give false information, such pharmacies are more likely to sell 
counterfeit, substandard, adulterated products or even not send anything. Internet can also facilitate access and thus support abuse of prescription drugs.
Taking into consideration the saftey of end user and making the online sale of drugs more protected and trustworthy, a few steps or regulations have been suggested in Figure 1.

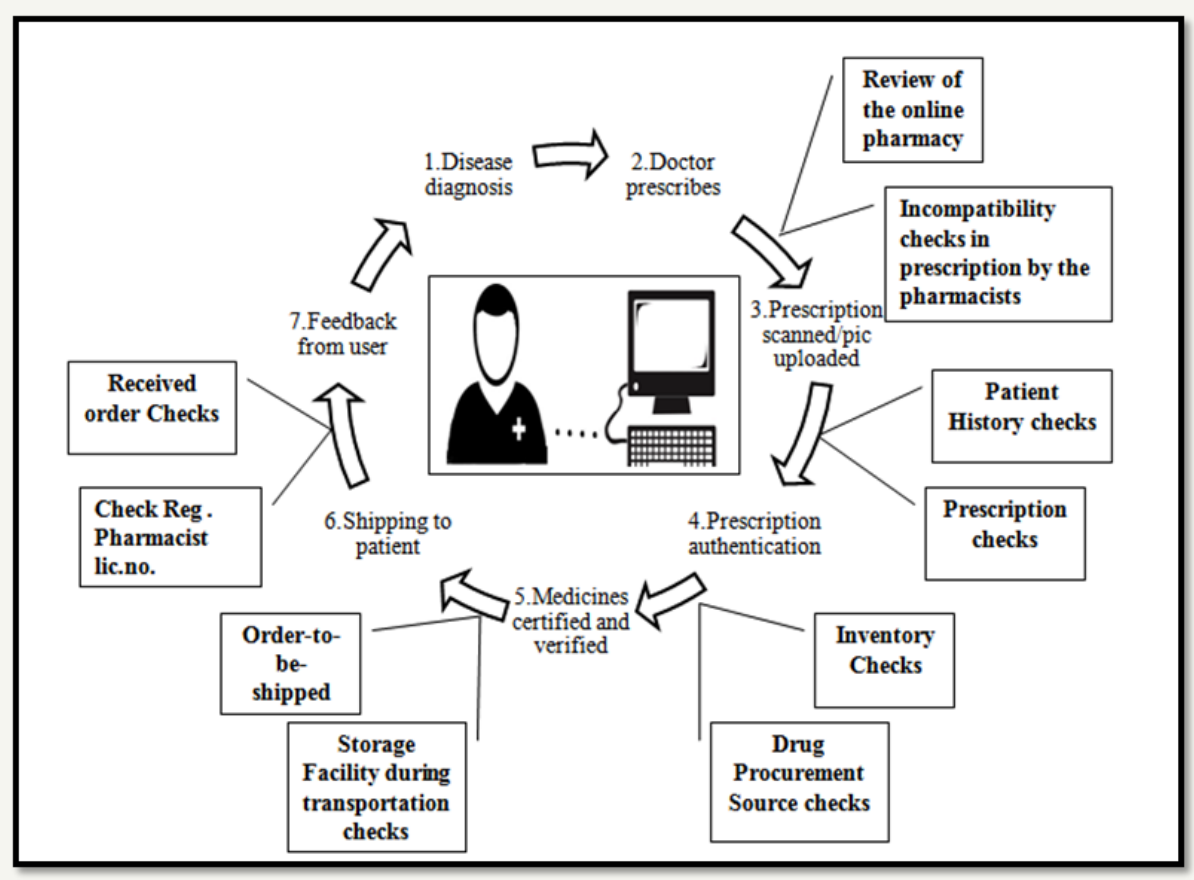

Figure 1: Suggested regulations for safe sale of drugs online.

Table 1: Recommendations for regulating Online sale of drugs.

\begin{tabular}{|c|c|c|}
\hline Steps & Actions & Remarks \\
\hline $\begin{array}{l}\text { 1. Disease diagnosis and } \\
\text { prescription by the doctor. }\end{array}$ & $\begin{array}{l}\text { Take appropriate prescription from a doctor, } \\
\text { preferably a digital prescription having } \\
\text { necessary details like doctors' registration } \\
\text { number, digital signature and date. }\end{array}$ & $\begin{array}{l}\text { Digital prescription needs to be uploaded directly on the website of } \\
\text { online pharmacy. Check for the authenticity of the online pharmacy } \\
\text { and listing in state-licensed websites within the country. }\end{array}$ \\
\hline $\begin{array}{l}\text { 2. Prescription scanned/ } \\
\text { picture uploaded and } \\
\text { Prescription authentication. }\end{array}$ & $\begin{array}{l}\text { Patient history checks. } \\
\text { Check for Incompatibilities. Check authenticity } \\
\text { of prescription. }\end{array}$ & $\begin{array}{l}\text { If the patient is already registered with the online pharmacy, his } \\
\text { history and the prescription are checked to prevent ADR. Register } \\
\text { the digital prescription in the online pharmacy records. }\end{array}$ \\
\hline $\begin{array}{l}\text { 3. Medicines certified and } \\
\text { verified }\end{array}$ & $\begin{array}{l}\text { Inventory checks. Drug procurement source } \\
\text { checks. Only those medicines that are produced } \\
\text { by licensed manufacturers must be procured. }\end{array}$ & $\begin{array}{l}\text { Bar codes/QR codes can be put on all medicines such that if the } \\
\text { user scans it, all the information of the medicines can be obtained } \\
\text { like the sellers' license, registration number and other necessary } \\
\text { details. }\end{array}$ \\
\hline 4. Shipping to patient & $\begin{array}{l}\text { Storage facilities during shipping must be } \\
\text { checked. }\end{array}$ & $\begin{array}{l}\text { For drug requiring special storage conditions, apt facilities will } \\
\text { enable maintenance of drug stability. }\end{array}$ \\
\hline 5. Feedback from user & $\begin{array}{l}\text { Received order checks. } \\
\text { Online pharmacy registration number checks. }\end{array}$ & $\begin{array}{l}\text { The patient/customer must confirm the intactness of the medicines } \\
\text { along with checking registration number of the online pharmacy. }\end{array}$ \\
\hline
\end{tabular}

The recommended regulations for sale of drugs through online pharmacies and justification for each recommendation is given in Table 1.

The medicnes will be procured from the inventory and only those medicines that have all the required codes will be dispatched after scanning. Automatically all the data will be stored in Governing body database that can be accessed anytime. This will ensure transparency and full control of the Governing body. Governing body can give list of defaulters, like somebody's license has expired or any counterfeiting of drugs going on. Such regn no. will be blocked and nobody can place orders to such a vendor. Also a feedback form could be filled by the customer that would highlight the adverse drug reactions if any, condition of the ordered medicines when delivered and service provided by the pharmacy.

\section{The Indian scenario:}

With the advent of online pharmacies, there is a rising need to for addendum of the Drugs and Cosmetics Act, 1940 that has no specific provision for online pharmacies from the pharmacy shops 
[4]. The e-pharmacy market shares contribute to an estimated $\$ 18$ billion in India and are growing steadily to become about $\$ 55$ billion by 2020. Many start-ups were launched in the year 2016, with the major chunk of investment gained by Netmeds (about $\$ 60$ million), followed by 1MG (about $\$ 6$ million) and Zigy (about $\$ 3.2$ million) [5]. The Drug Controller General of India had stated that it was important to regulate the online pharmacies without hampering the safety. Currently, the Pharma Act has no clearness on electronic prescriptions. However, the IT Act states that a document's digital copy is valid if an original copy is presented during verification [5]. The present online pharmacies are thus following this rule which creates more opportunities for illegitimate sale of drugs online. This could give rise to drug abuse, improper sale of drugs and even counterfeiting of drugs.

\section{The US FDA has suggested a few steps to stay safe from counterfeit drugs [6]:}

a. Buying of medicines only from in house pharmacy websites that are state-licensed in the U.S.

b. Prevention from buying prescription medicines that are sold without asking for a prescription.

c. Prevention of buying medicines from an online store that does not encourage prior medical examination by the doctor or even filling an online KYC questionnaire before selling medicines for the first time.

d. Valid pharmacy license check must be done with your state authority of pharmacy or the National Association of Boards of Pharmacy for ensuring the quality decided by the state.

e. Look for lucid and easily comprehensible privacy and security policies.

f. Prevention of sharing any personal information which could include social security number or code, credit card details, or medical or health history-without having guarantee that the information would be kept safe and private

g. Use of legitimate websites that provide assistance of a licensed pharmacist to answer any questions.

To implement these guidelines, the USFDA has launched an auxiliary site called www.BeSafeRx.com where the authenticity of each online pharmacy can be checked. Besides, many other sites have come up like www.pharmacychecker.com which work on the same lines.

Other organizations involved in safety of online sale of drugs:

1. United Nations Office on Drugs and Crime (UNODC: Counterfeit-Don't Buy Into Organized Crime

2. NIH National Institute on Aging: Beware of Health Scams
3. NIH Office of Dietary Supplements: How To Evaluate Health Information on the Internet

4. Federal Trade Commission's Bureau of Consumer Protection

5. Drug Enforcement Administration: Report Suspicious Internet Pharmacies

6. NABP - State Boards of Pharmacy

7. U.S. Customs and Border Protection: Restrictions on Prescription Drugs

\section{Conclusion}

Harnessing the advanced technology, in a way that does not harm the public but rather proves to be beneficial to mankind is the need of the time. Online pharmacies can be looked at as a step towards facilitating the availability of medical help even to the remote areas and thus improvising the healthcare system. However, the points to be taken into consideration are the prevention of illegal sale of drugs and end motive of securing our health. Addendum in the general laws and regulations governing the sale of drugs, both through online and offline pharmacies, is recommended. Stringent checks at various stages of the sale of drugs over the internet would assure its safety and also build the patients trust thus boosting the online business. A positive transition in the healthcare systems is potentially expected through the use of such advanced technologies to reach every nook and corner of countries and provide medical help.

\section{Acknowledgement}

We would like to acknowledge SVKMs NMIMS School of Pharmacy \& technology Management for providing us the necessary and valuable support to complete this review article.

\section{References}

1. Internet Pharmacy warning letters, U.S. Food and Drug Administration, Updated on February 2, 2017. https://www.fda.gov/Drugs/DrugSafety/ DrugIntegrityandSupplyChainSecurity/ucm348680.htm Accessed on May 5, 2017.

2. Orizio G, Merla A, Schulz PJ, Gelatti U (2011) Quality of Online Pharmacies and Websites Selling Prescription Drugs: A Systematic Review. J Med Internet Res 13(3): e74.

3. Brushwood DB (2001) Responsive regulation of Internet pharmacy practice. Annals of Health Law 10: 75-103.

4. Aggarwal KB (2016) Need to amend Drugs and Cosmetics Act 1940 to promote e-pharmacy in India, FICCI Media Division.

5. Will online pharmacies work in India, and are they even legal? www. livemint.com, Modified on January 14, 2016. https://www.livemint. com/Companies/Will-online-pharmacies-work-in-India-and-are-theyeven-legal.html Accessed on February 10, 2016.

6. The possible dangers of buying medicines over the internet, U.S. Food and Drug. 
Creative Commons Attribution 4.0 International License

For possible submissions Click Here
Submit Article

\section{AICS}

\section{Advancements in Case Studies}

\section{Benefits of Publishing with us}

- High-level peer review and editorial services

- Freely accessible online immediately upon publication

- Authors retain the copyright to their work

- Licensing it under a Creative Commons license

- Visibility through different online platforms 